\title{
English negative concord and double negation: The division of labor between syntax and pragmatics
}

\author{
Frances Blanchette, Marianna Nadeu, Jeremy Yeaton \& Viviane Déprez*
}

\begin{abstract}
Recent research demonstrates that prototypical negative concord (NC) languages allow double negation (DN) (Espinal \& Prieto 2011; Prieto et al. 2013; Déprez et al. 2015; Espinal et al. 2016). In NC, two or more syntactic negations yield a single semantic one (e.g., the 'I ate nothing' reading of "I didn't eat nothing"), and in DN each negation contributes to the semantics (e.g. 'It is not the case that I ate nothing'). That $\mathrm{NC}$ and $\mathrm{DN}$ have been shown to coexist calls into question the hypothesis that grammars are either NC or DN (Zeijlstra 2004), and supports microparametric views of these phenomena (Déprez 2011; Blanchette 2017). Our study informs this debate with new experimental data from American English. We explore the role of syntax and speaker intent in shaping the perception and interpretation of English sentences with two negatives. Our results demonstrate that, like in prototypical NC languages (Espinal et al. 2016), English speakers reliably exploit syntactic, pragmatic, and acoustic cues to in selecting an NC or a DN interpretation.
\end{abstract}

Keywords. negative concord; double negation; syntax; pragmatics; experimental linguistics

1. Introduction. Consider the following sentence:

(1) Maria didn't eat nothing today.

Sentence (1) has two syntactic negations, -n't and nothing, and two possible interpretations. In one interpretation, the two syntactic negations act in concord to contribute a single semantic negation, the so-called negative concord (NC) reading. In the other, each negation contributes independently to the semantics, forming a double negation (DN) reading, logically equivalent to an affirmative. The two readings can be paraphrased as follows:

(1a) NC: Maria ate nothing today. (alt: Maria didn’t eat anything today.)

(1b) DN: It is not the case that Maria ate nothing today. (=She ate something.)

In current linguistic theory, the two readings of (1) are typically assumed to belong to two different English grammars: While the NC reading is associated with "non-Standard" English speakers, "Standard English" is assumed by many to be a "DN language" (De Swart 2010; Espinal \& Tubau 2016; Ladusaw 1992; Longobardi 2014; Puskás 2012; Zeijlstra 2004, and others). This paper presents experimental evidence that contradicts this assumption, showing that Standard English speakers reliably exploit syntactic and pragmatic cues to generate both NC and DN readings of sentences with two negatives.

\footnotetext{
* We are grateful to Deborah Morton for allowing us to recruit naïve speakers from her introductory linguistics class at Penn State in order to generate the stimuli, to Meagan Daily and Lisa Cox for providing research assistance, and to Clara Cohen for helpful feedback and suggestions. We are also very grateful to Penn State's Center for Language Science, which provided funds for participant stipends as well as facilities for generating the acoustic stimuli. Authors: Frances Blanchette (fkb1@psu.edu, Penn State University), Marianna Nadeu (Independent Researcher), Jeremy Yeaton (École Normale Supérieure), and Viviane Déprez (Rutgers University).
} 
The paper is structured as follows. Section 2 presents some background on NC and DN, including previous experimental research on negation in Romance languages as well as English. Section 3 details the methods we employed in our perception experiment, and section 4 presents our research questions and hypotheses. In section 5 we present the results of our perception task, which show that both syntax and speaker intent predict whether a sentence with two morphological negations will be interpreted as NC or DN, as well as preliminary analyses of the acoustic properties associated with these two readings. Section 6 summarizes and discusses some broader implications of our experimental findings, including the implication that "Standard English" should henceforth be modeled as a "negative concord language".

2. Background. Predominant syntactic theories assume a fundamental distinction between NC and DN (or non-NC) languages. In Zeijlstra's (2004:8) terms, "languages exhibit either syntactic or semantic negation". Under this theory, NC languages, in which negative elements typically appear to act in concord with one another in a clause, are the reflection of a system of syntactic negation. $\mathrm{DN}$, on the other hand, reflects a system in which a unique semantic negation underlies each surface syntactic occurrence of negation. Following this view, once a child has determined which type of language she is acquiring, her linguistic performance should reflect a general and overall bias toward either $\mathrm{NC}$ or DN, and this biased behavior is expected to solidify as the child converges on her adult language (Thornton et al. 2016).

Déprez (2011) takes a different view of language design with respect to negation, observing that "within language diversity appears to be more often the rule than the exception” (p. 225). In contrast with Zeijlstra's (2004) two different grammars approach, Déprez's "micro-parametric" view suggests that distinct syntactic configurations will yield either $\mathrm{NC}$ or DN readings in a given language. In this section, we review previous experimental work which shows unequivocally that $\mathrm{NC}$ and $\mathrm{DN}$ coexist in prototypical Romance languages, and which suggests that Standard English speakers also generate both NC and DN.

\subsection{Previous EXPERIMENTAL WORK ON ROMANCE. A growing body of experimental work} suggests that, for prototypical NC languages like Catalan, Spanish, and French, speakers reliably generate DN in a particular set of pragmatic contexts with marked prosody, and conditioned by syntactic structure. In their study of Catalan, Espinal \& Prieto (2011) show that negative word answers (e.g., nothing) to negative yes/no questions (e.g., What didn't you eat?) can be interpreted either as singly negative ('I ate nothing') or as a double negation ('there is nothing that I did not eat'). In the DN reading, the negative word serves the pragmatic function of denying presupposition contributed by the question, in this case, that something was not eaten (Geurts 1998). Espinal \& Prieto's results show that in Catalan, the DN reading is available and reliably associated with a marked contradictory intonation contour (Liberman \& Sag 1974). Extending this line of research to examine Catalan alongside Spanish, Prieto et al. (2013) demonstrate that in addition to marked prosody, gesture is also a reliable predictor of DN readings in these prototypical NC languages.

Déprez et al. (2015) show that syntax also plays a role in determining the likelihood of a $\mathrm{DN}$ or an NC reading in Catalan. The following illustrates an example item from one condition of their experimental study (ex. (23a), p. 87):

(2) Cap dels alumnes (no) llegeix cap llibre.

None of.the students NEG reads no book

NC: 'None of the students read a book.'

DN: 'None of the students do not read a book.' (=All of the students read.) 
Sentence (2) contains a negative subject cap dels alumnes 'none of the students', a negative object cap llibre 'no book', and an optional preverbal negative marker (no). Déprez et al. show that the preverbal marker shapes interpretation for Catalan speakers, who gave more DN responses for sentences like (2) when the marker was present than when it was absent. Extending this work, Espinal et al. (2016) examine the effects of pragmatic context, syntax, and prosody in Spanish and Catalan. Their results confirm previous findings that DN readings are readily available under the right pragmatic conditions and with marked prosody, and show further that syntax also shapes the availability of DN readings in Spanish. Most recently, Déprez \& Yeaton (to appear) examine the coexistence of NC and DN in French, showing that French speakers also reliably mark DN relative to single negation NC readings. These authors find that in French, DN is marked with a higher fundamental frequency followed by a significant f0 drop as compared with NC.

Synthesizing results from previous experimental work on Romance, it is clear that speakers of "NC languages" exploit syntactic, prosodic, and pragmatic cues to access and produce both NC and DN constructions. The evidence thus demonstrates that "NC languages" systematically and readily generate DN alongside single negation interpretations, in support of a micro-parametric view of language design with respect to negation.

2.2 Negative CONCORD IN STANDARD EngLish. Testing the limits of Déprez's (2011) microparametric view, we might also wish to investigate whether there is evidence for NC in "DN languages", such as Standard English. The question is complicated by the fact that NC constructions are associated with a heavy social stigma in English-speaking societies, dating back to even before Bishop Robert Lowth's $18^{\text {th }}$-century edict that, in English, two negatives should equal a positive (Horn 2010). A further complication is that there is little agreement, from a linguistic perspective, on precisely what constitutes Standard English (Lippi-Green 1997:53). Interestingly, $\mathrm{NC}$ itself appears to play an important role in distinguishing Standard from non-Standard English speakers. Nevalainen (1998) illustrates this on the basis of historical corpus data, arguing that NC is in fact a universal of "vernacular" Englishes, and that the shift away from NC in usage was employed as a marker of climbing social status. Synchronically, Wolfram \& Fasold (1974) observe that NC is a feature of virtually all American Englishes except for the Standard variety. We therefore adopt the view, for the purpose of this paper, that Standard (American) English speakers are those who do not use NC.

Blanchette $(2013,2015)$ hypothesizes that, despite the overall unacceptability and apparent absence of NC in Standard English usage, NC is nevertheless generated by all English varieties, including the Standard. Under this hypothesis, and under the definition of Standard English employed here, speakers who do not accept or report using NC should nevertheless display grammatical knowledge of it. This hypothesis is supported by experimental evidence in Blanchette (2017), in a series of gradient acceptability studies of English sentences with two negatives. Her results demonstrate that Standard English speakers reliably distinguish between NC structures, and even prefer them over DN in certain syntactic configurations. To illustrate, consider the following example stimuli:

(3) He didn't take nobody on the trip.

(4) Nobody didn't help patients on that day.

The examples each contain the marker didn't as well as the phrase nobody, which resides in direct object position in (3) and canonical subject position in (4). Each test item in the experiment was preceded by a single context sentence designed to elicit either an NC or a DN interpretation of the 
test items. For example, sentence (3) was preceded by either (3a) or (3b), and sentence (4) was preceded by (4a) or (4b):

(3a) NC context: John went on vacation all alone.

(3b) DN Context: Mary said John went on vacation all alone.

(4a) NC Context: The hospital was closed because of the storm.

(4b) DN Context: All the doctors treated patients at the hospital.

Participants were asked to rate the naturalness of the sentences in context on a scale of 1-7.The results revealed that, though unacceptable overall (with mean ratings below the median 4), participants displayed a significant preference for object sentences like (3) in NC contexts, and for subject sentences like (4) in DN contexts.

To determine whether this result reflected a true subject-object asymmetry, Blanchette (2017) further compared structures like (3) and (4) in NC contexts with structures like (5), in which didn't precedes a negative subject: ${ }^{1}$

(5) Didn't nobody finish their food at breakfast.

'Nobody finished their food at breakfast.'

The results replicated the preference for NC sentences with a negative object over those with a negative subject, but revealed no difference between the object sentences like (3) and post $-n$ 't subject sentences like (5). Taken together, these acceptability judgment results suggest that the position of the marker $-n$ ' $t$ relative to the negative phrase plays a crucial role in both the acceptability and interpretation of sentences with two negations as either NC or DN, in Standard English.

Blanchette \& Nadeu (2018) further show that American English speakers generate both single and double negation readings of negative words used as responses to negative yes/no questions in an experiment design similar to Espinal \& Prieto's (2011) study of Catalan. Crucially for our purposes, their results demonstrate that single and double negation readings are reliably distinguished via acoustic cues. Specifically, when the pragmatic context calls for a DN interpretation, speakers reliably mark the negative word via higher fundamental frequency as compared with the single negation reading.

In sum, previous work on Standard English demonstrates that syntax shapes acceptability, and that judgments are not straightforwardly preferential toward either DN or NC, but rather vary by syntactic structure. We have further seen that acoustic cues can play a role in distinguishing between single and double negation readings of negative elements. The current study seeks to inform and extend these previous findings, using a perception task based on productions of sentences with two negatives by Standard English speakers. The perception task provides us with a measure that is more similar to previous work on Romance, thus providing a better means for comparison across languages. As such, the results of our perception task contribute toward answering the broader question of whether and how grammars, in general, generate NC and DN. Additionally, the perception task and accompanying acoustic analyses provide an alternative measure to acceptability judgment experiments, which, given the normative pressures associated with English NC, are limited in their ability to capture speaker competence.

\footnotetext{
${ }^{1}$ Sentences like didn't nobody eat, first described by Labov et al. (1968), are a form of the Negative Auxiliary Inversion construction, which is string-equivalent to a yes/no question, but employed as a declarative in many American English varieties.
} 
3. Research questions and hypotheses. The study aimed to investigate two main questions. First, we asked whether, like speakers of prototypical NC languages, Standard English speakers generate both NC and DN readings of negative sentences in a predictable set of syntactic conditions. Based on Blanchette's (2017) acceptability judgment experiment results, we hypothesized that the position of the marker $-n$ 't relative to the negative phrase would influence how participants interpreted the test sentences, with a preference for $\mathrm{NC}$ when the marker precedes the negative phrase, and DN when the marker follows the negative phrase. Alternatively, under the hypothesis that Standard English is a "DN language" that does not have NC, speakers should reliably select the DN reading most or all of the time, regardless of syntactic structure.

Our second primary aim was to determine whether and how Standard English speakers' interpretations of sentences with two negatives are driven by acoustic cues in the speech signal, generated under specific pragmatic conditions. We hypothesized that speakers whose grammars allow NC would reliably use the prosodic cues associated with this reading, while speakers whose grammars only allow DN would not. On the basis of Blanchette and Nadeu's (2018) results, we further hypothesized that DN readings would be prosodically marked relative to NC, possibly by higher f0.

4. Methods. In this section we describe how we generated the auditory stimuli for the perception task, as well as how the perception task was designed. We also describe the methods we used to analyze the data.

4.1 THE AUDITORY STIMULI. Our critical stimuli, each of which included two negations, were designed using three syntactic conditions. They included (i) 16 items with subject no one and object nothing (2Q); (ii) 16 items with the negative auxiliary won't and nothing in object position (Ob); and (iii) 16 items with no one in canonical subject position, immediately preceding won't (Sub). Table 1 illustrates example items for the three syntactic conditions.

\begin{tabular}{|l|l|}
\hline \multicolumn{1}{|c|}{ Syntactic Condition } & \multicolumn{1}{c|}{ Example Item } \\
\hline Two negative quantifiers $(\mathbf{2 Q})$ & No one will love nothing when it gets cold. \\
\hline won't + negative object $(\mathbf{O b})$ & Lina won't load nothing on the truck. \\
\hline Negative subject + won't $(\mathbf{S u b})$ & No one won't owe payment to the college. \\
\hline
\end{tabular}

Table 1. Syntactic conditions and example items for the elicited stimuli

Each item was presented in a context intended to elicit either a NC or a DN reading. Each item included a single context sentence, the critical item, and a True/False verification question to determine whether participants interpreted the sentence as the context intended (as NC or DN). The following illustrates an item with all three components:

Context: Lisa managed to ruin every dish.

Sentence (Sub): No one won't love the food this Thanksgiving.

True or False: People will dislike the dishes at Thanksgiving dinner.

Note that the context in (6) elicits a single negation NC reading of the two negatives sentence: If Lisa ruined every dish, then no one will love the food. The correct answer to the verification question is therefore True, since disliking the dishes entails that people did not love them. In 
addition to the items with two negatives, a control condition with a single negation (subject no one or object nothing) was also included.

21 Penn State native speakers of American English were recruited from an undergraduate introductory linguistics class to generate the auditory stimuli. Speakers sat in a sound attenuated booth in a campus laboratory. The stimuli were presented electronically using E-Prime 2 Software (Psychology Software Tools, Inc. 2012). A keyboard was used for navigation through the experiment and for entering responses. The context, sentence, and verification questions were presented on separate screens. All items and instructions were in black print on a white backdrop except for the screen with the negative sentence, which had the text in green. Participants were instructed to say the sentence in green aloud, as though they were responding to the context. Oral responses were recorded using a Fostex DC-R302 recorder and a head-mounted Audix HT5 condenser microphone. The stimuli were digitized at $44.1 \mathrm{kHz}, 16 \mathrm{bit}$.

Figure 1 illustrates percentages of participants' correct responses to the verification question for the experimental items and the single negative controls in the stimuli elicitation task.

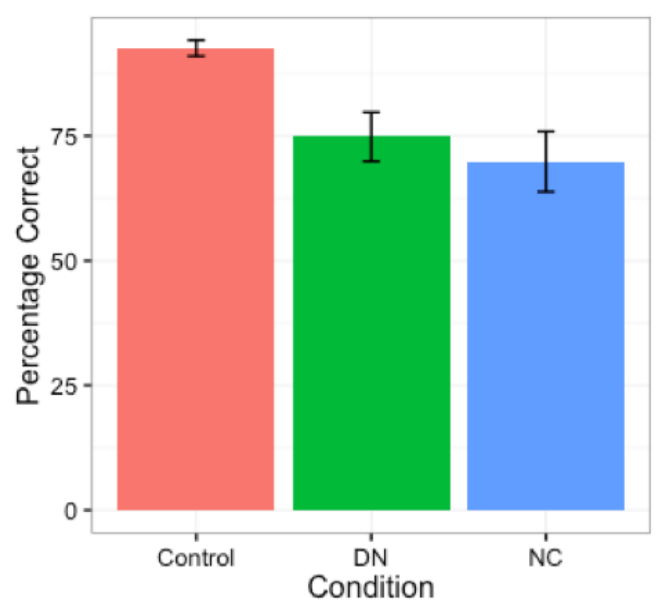

Figure 1. True/False verification responses by pragmatic condition in stimuli elicitation task

The figure shows participants' relatively high rates of correct answers to the True/False verification questions, at over $70 \%$ in both the $\mathrm{DN}$ and the $\mathrm{NC}$ conditions. The sound files ( $\mathrm{n}=$ 649) that corresponded to the correct verification question answers in the DN and NC conditions, as shown in Figure 1, were used as stimuli for a perception task.

4.2 THE PERCEPTION TASK. 110 adult native speakers of American English were recruited via Amazon's Mechanical Turk to participate in the perception task. Participants listened to the sound files with the context removed, then selected a paraphrase of the item that corresponded to an NC or a DN interpretation. Table 2 illustrates an example item with the two meaning choices in each of the three syntactic conditions. 


\begin{tabular}{|l|l|l|}
\hline \multicolumn{1}{|c|}{ Item } & \multicolumn{1}{|c|}{ NC Meaning } & \multicolumn{1}{c|}{ DN Meaning } \\
\hline $\begin{array}{l}\text { No one will love nothing when } \\
\text { it gets cold. }\end{array}$ & $\begin{array}{l}\text { People will be miserable in the } \\
\text { cold weather. }\end{array}$ & $\begin{array}{l}\text { People will find ways to enjoy } \\
\text { the cold weather. }\end{array}$ \\
\hline $\begin{array}{l}\text { Lina won't load nothing on the } \\
\text { truck. }\end{array}$ & $\begin{array}{l}\text { Lina will refuse to help load the } \\
\text { truck. }\end{array}$ & Lina will help load the truck. \\
\hline $\begin{array}{l}\text { No one won't owe payment to } \\
\text { the college. }\end{array}$ & $\begin{array}{l}\text { All students will have paid their } \\
\text { tuition. }\end{array}$ & $\begin{array}{l}\text { All students will owe tuition } \\
\text { money. }\end{array}$ \\
\hline
\end{tabular}

Table 2. Items and meaning paraphrases for the perception task stimuli

The sound files were divided across ten different surveys, and each participant listened to approximately 65 tokens. Items with DN and NC interpretations were balanced within the surveys, as were items from each syntactic condition. In addition to selecting an NC or a DN meaning for each token, participants were also asked to rate how confident they were with their response to each item on a scale of one to seven.

4.3 POST-TASK QUESTIONNAIRE. After completing the task, participants were asked to fill out a brief questionnaire about their background and language use. This revealed that participants were from all over the U.S. (35/50 states represented) with ages ranging from 22 to 67 (mean age 37.9). In terms of their schooling, the majority (69) were college educated, with 16 reporting graduate studies, and 25 reporting a high school education. In addition, most of our participants (59) reported to having suburban upbringings, 30 were raised in urban areas, and 21 were from rural areas. 33 of our 110 participants reported to having some musical training, which could aid in the task due to higher sensitivity to f0 variations (Cummins et al. 2006; Schellenberg 2002).

In addition to this demographic information, we also wished to determine participants' $\mathrm{NC}$ usage. We therefore included the questions in (7) through (9). We note, however, that given the social stigma associated with $\mathrm{NC}$, despite the fact that the survey was anonymous, participants' self-reports should be interpreted with caution.

(7) Object NC: Imagine a situation in which you have finished dinner, and you want to tell someone that dessert was not a part of your meal. Which of the following would you be more likely to say?
(a) I didn't have no dessert.
(b) I didn't have any dessert.
(c) Either (a) or (b)

(8) Subject NC: Imagine a situation in which you threw a party, but all the people you invited decided to do something else instead of attending your party. In that situation, would it be natural for you to say "Nobody didn't come to my party"?
(a) Yes
(b) No

(9) 2Q NC: Imagine a situation in which you and a group of friends tried to watch a movie but the screen was broken. Which of the following would you be more likely to say?
(a) Nobody watched nothing.
(b) Nobody watched anything.
(c) Either (a) or (b)

With the caveat regarding the effects of normative pressure mentioned above, we report that participants' responses to questions (7) through (9) suggest a near categorical lack of NC usage. 
For question (7), one participant answered (a), three participants answered (c), and the remaining 107 answered (b). Question (8) yielded four (a) responses, while the remaining 107 answered (b). For question (9), there was one (a) response, four (c) responses, and 106 (b) responses. These responses suggest that, overall, our sample of Mechanical Turk workers represents a Standard English speaking fragment of the population.

4.4 ANALYSES. The stimuli for the perception task included a total of 649 audio files, which generated 7,139 responses to the comprehension questions (11 responses per token), and the same number of confidence ratings. The responses were analyzed statistically in $\mathrm{R}$ using linear and general linear mixed effects regression models (Bates et al. 2015).

We also conducted preliminary analyses of the sound files used as stimuli in order to investigate which acoustic cues could be guiding participants' interpretations. Features such as duration and f0 were extracted in Praat (Boersma \& Weenink 2016). For the f0 data, we used the ProsodyPro software (Xu 2013), which extracts time normalized f0 values at ten equidistant points across a single syllable. We z-score transformed these f0 values in order to compare across speakers, and we analyzed them statistically using smoothing spline (SS) ANOVAs (Gu 2014; see also, e.g., Davidson 2006; Mathes 2015; Simonet et al. 2008). In the SS ANOVA model, splines are fitted to the data within each condition (e.g., NC vs. DN), and then Bayesian confidence intervals are plotted along the curves for visual comparison. The lack of overlap between the confidence intervals is interpreted as a statistically significant difference (see figures 4 and 5 below).

5. Results. This section details the results of the perception task, as well as preliminary acoustic analyses of the sound files employed as stimuli.

5.1 PERCEPTION TASK RESULTS. Figure 2 illustrates participants' rate of NC responses, that is, the responses for which they chose the single negation paraphrase for the two negatives sentence in the audio-perception task. The responses are separated by speaker intent, which was either DN or NC. (Recall that the True-False verification question in the stimuli elicitation task served as a measure of speaker intent, and only the audio files for which the verification question was answered correctly were included in the experiment.)

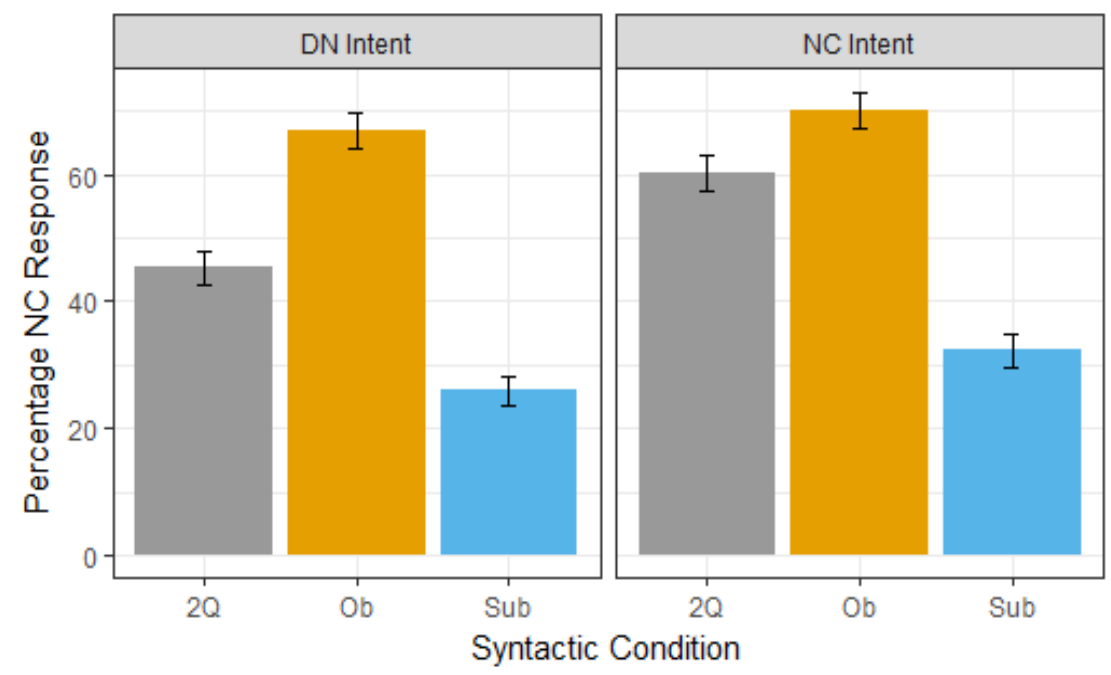

Figure 2. Percentage NC response by syntactic condition and speaker intent 
A general linear mixed effects regression on the response data revealed that participants were significantly more likely to give NC interpretations in the Object than in the Subject and 2Q conditions $(\beta=1.71, \mathrm{SE}=.20, p(\mathrm{z})<.001)$. That is, regardless of speaker intent, participants preferred to give NC interpretations in the object condition. The reverse pattern is observed for the Subject condition, in which participants were more biased toward DN interpretations, regardless of speaker intent: In both cases, NC responses were well below 35\%. However, further analyses revealed that speaker intent did in fact impact interpretation, in that participants were significantly more likely to give $\mathrm{NC}$ responses when the speaker intended $\mathrm{NC}(\beta=.40, \mathrm{SE}=.19, p(\mathrm{z})<.05)$.

The effect of speaker intent can be observed most clearly in the $2 \mathrm{Q}$ condition, in which responses trended in the direction of speaker intent in both pragmatic conditions. Note further that responses in the $2 \mathrm{Q}$ condition were relatively close to chance in the $\mathrm{DN}$ intent condition at $45 \%$ $\mathrm{NC}$, but more biased toward $\mathrm{NC}$ in the $\mathrm{NC}$ intent condition, at $61 \% \mathrm{NC}$ responses. We discuss this finding further below.

Figure 3 illustrates participants' confidence ratings by response (rows) and by speaker intent (columns). A general linear mixed effects regression model with participants' mean confidence ratings as the dependent variable revealed higher confidence when the selected response aligned with speaker intent $(\beta=.06, \mathrm{SE}=.02, p(\mathrm{z})<.005)$. The analysis further revealed an effect of syntax, such that participants were more confident with their NC responses in the Object condition than in either the Subject or the $2 \mathrm{Q}$ conditions $(\beta=.10, \mathrm{SE}=.02, \mathrm{p}(\mathrm{z})<.001)$.

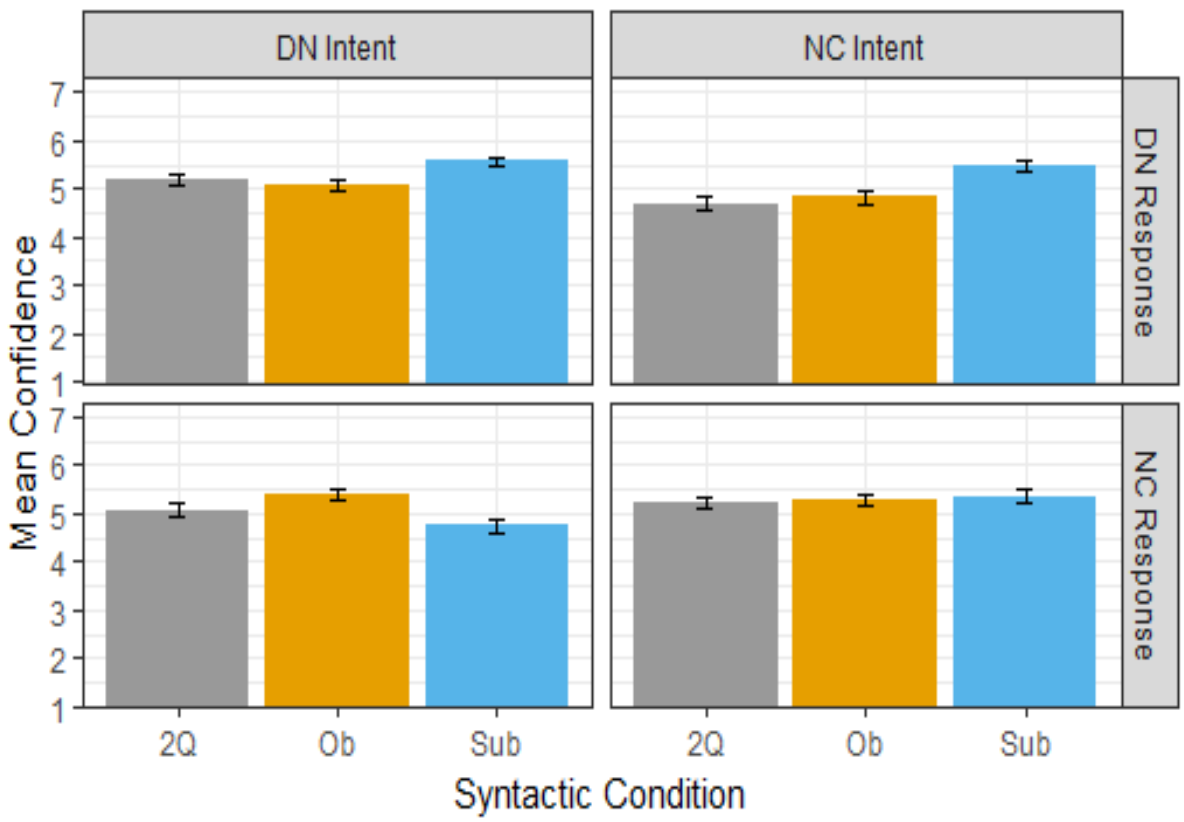

Figure 3. Confidence (1-7) by syntactic condition (2Q, Ob, Sub) and speaker intent (DN, NC)

The results of the confidence ratings analyses provide further confirmation that speakers were employing acoustic cues in the speech signal as well as syntactic information to select their interpretation. Of particular note in both the interpretation percentages and the confidence ratings is the bias toward NC interpretations for objects and DN interpretations for subjects when the marker $-n$ 't (or won't) was included. In light of the fact that interpretation patterned in the direction 
of speaker intent in the 2Q condition, when the marker was not included, this finding suggests that the marker plays a crucial role in shaping interpretation and confidence.

We note that this particular syntactic effect of the position of the negative marker relative to the negative phrase replicates the pattern in Blanchette's (2017) acceptability judgment studies, but with a different type of data, namely, judgments of meaning. We discuss the relationship between these two sets of findings further in the concluding section.

5.2 PRELIMINARY ACOUSTIC ANALYSES. Our analyses of responses to participants' interpretation choices and confidence in their choices for the auditory stimuli displayed significant effects of speaker intent. Recall that speaker intent corresponds to a correct answer to a comprehension question during the stimuli elicitation task. For example, stimuli coded as "DN intent" corresponded to sentences produced in a context that elicited a DN interpretation, and for which the speaker selected the response to the True/False verification question that matched the DN interpretation. The significant effects of speaker intent on interpretation and confidence indicate that the speakers who generated the stimuli were employing acoustic cues in order to convey this difference in meaning. We therefore conducted preliminary acoustic analyses, in order to locate the acoustic correlates of speaker intent corresponding to NC and DN readings.

Figures 4 and 5 show the results for two separate SS ANOVA analyses, one on the auxiliary won't in the Subject condition (Fig. 4), and one on the subject no one in the 2Q condition (Fig. 5).

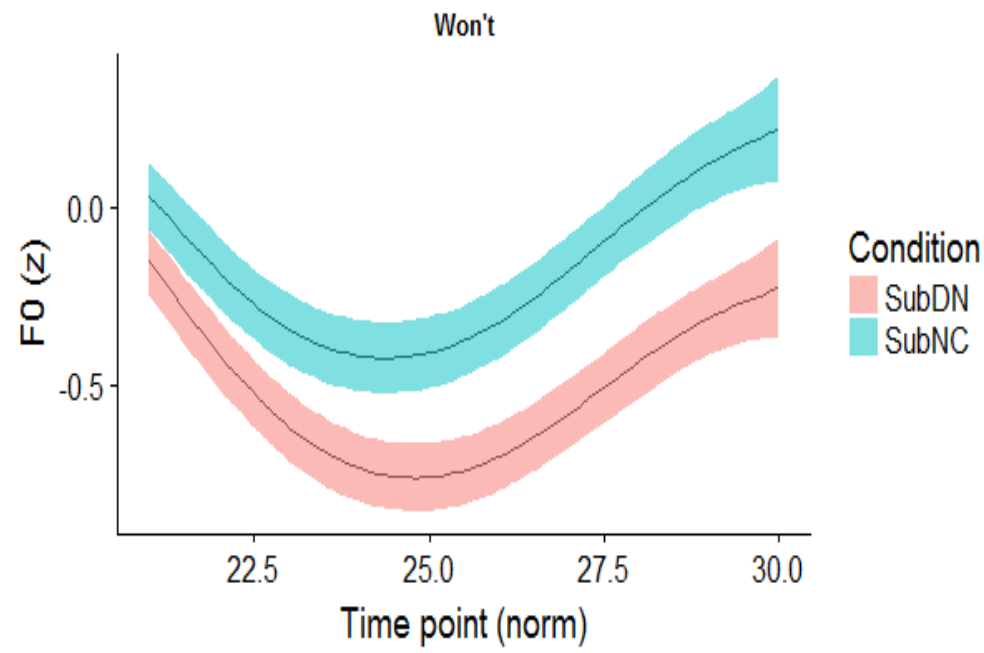

Figure 4. Smoothing splines and 95\% Bayesian confidence intervals for the f0 curves corresponding to auxiliary won't in the Subject condition 


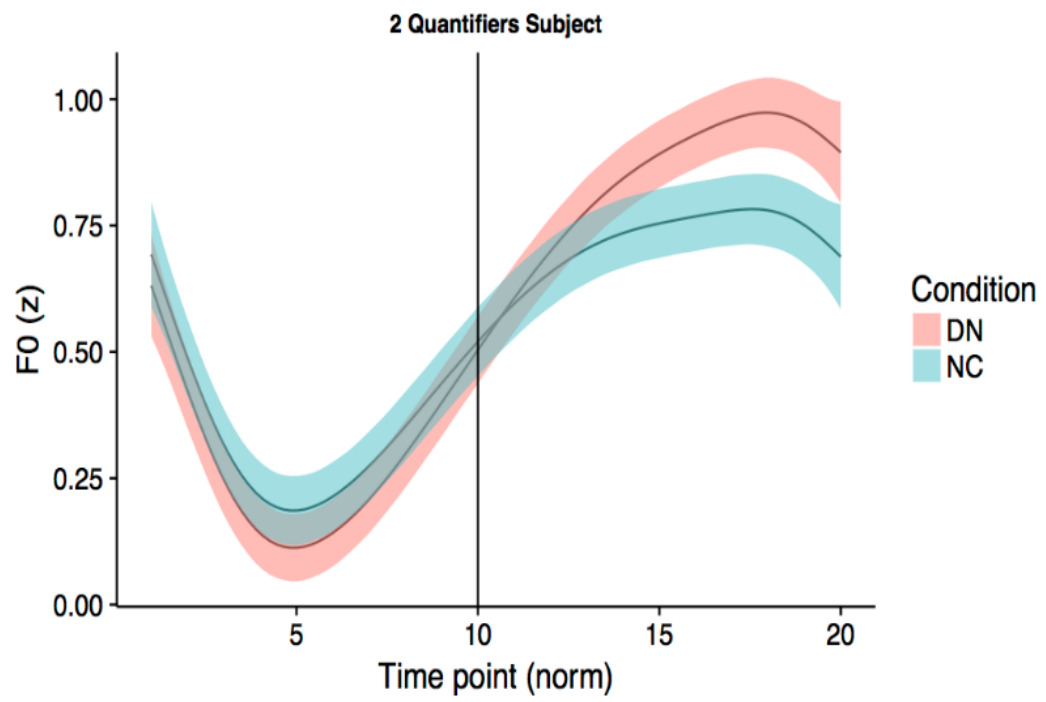

Figure 5. Smoothing Spline ANOVA for subject no one in the 2Q condition

As the figures show, the difference in $\mathrm{f0}$ between the $\mathrm{NC}$ and $\mathrm{DN}$ conditions is most pronounced on won't in the Subject condition (e.g., No one won't love the food this Thanksgiy,ing that there is virtually no overlap in the f0 curves. Figure 4 shows that, in this syntactic condition, won't has a significantly lower f0 for DN than it does for NC. In the 2Q condition (Fig. 5), there is a significant difference on the second syllable of subject no one, but in the reverse direction: DN is distinguished from NC in being marked by significantly higher fundamental frequency, in a manner similar to but less pronounced than the findings in Blanchette \& Nadeu (2018).

Figure 6 illustrates an acoustic cue associated with a meaning difference in the Object condition, namely, the duration of the stressed syllable in nothing relative to the whole word, compared across pragmatic conditions (and with the single negative control, e.g., Ronnie will love nothing at the restaurant). Here, unlike Blanchette \& Nadeu (2018), we did not find a significant difference in fundamental frequency for the negative object across pragmatic conditions. The observed difference in Figure 6 is small but significant and serves to distinguish $\mathrm{DN}$ from both the $\mathrm{NC}(\beta=.02, \mathrm{SE}=.01, \mathrm{t}=2.53)$ and the Control conditions $(\beta=.02, \mathrm{SE}=.01$, $\mathrm{t}=2.37$ ).

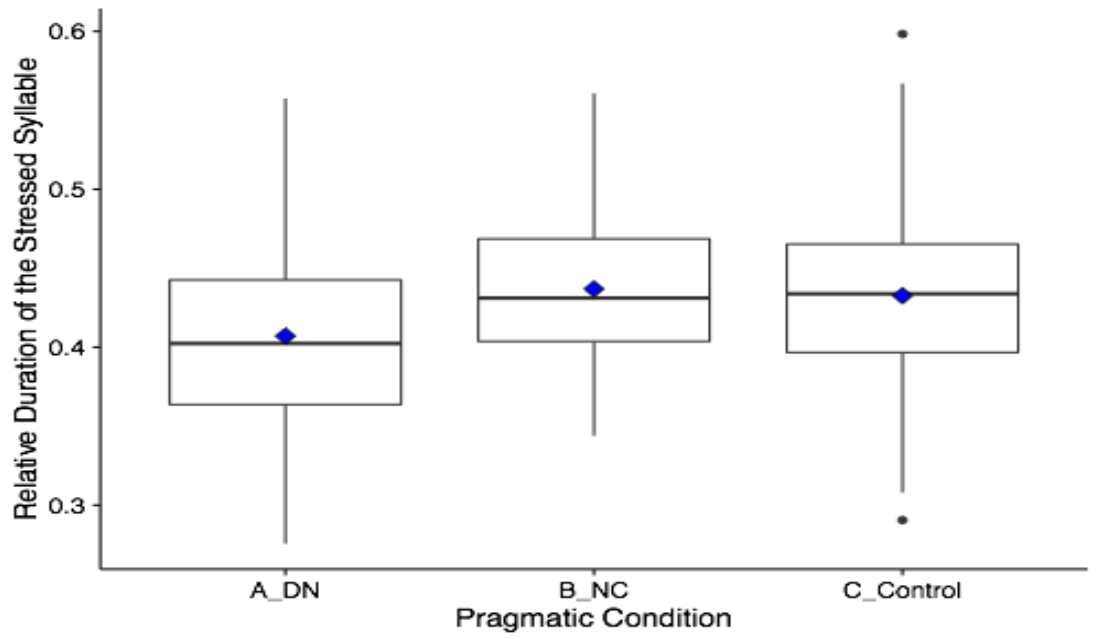

Figure 6. Relative duration of the stressed syllable of nothing in the Object condition 
6. Conclusions and discussion. Our results demonstrate clearly that, like in prototypical NC languages, both NC and DN interpretations are available in English, and that syntax and pragmatics (or speaker intent) play unique roles in the interpretation of sentences with two negatives. Our participants, who we categorize as Standard English speakers on the basis of a post-task questionnaire, reliably employed syntactic information and exploited acoustic cues in the speech signal to select an NC or a DN interpretation. We therefore conclude that our results present clear support for "micro-parametric" over "macro-parametric" theories of the syntax of negation. Furthermore, our results strongly suggest that Standard English is not a "DN language" after all, and that the apparent lack of NC is only a surface phenomenon.

6.1 THE EFFECT OF SYNTAX. As noted above, the inclination toward Object NC and Subject DN interpretations found in the results of our perception task replicates the findings in Blanchette's (2017) study of gradient acceptability judgments. Taken together, these findings suggest a grammatical architecture in the variety (or varieties) of English under study in which sentences with a negative object (or phrase) following a negated auxiliary are biased toward an NC interpretation, and sentences with a negative subject in canonical position preceding a negated auxiliary are biased toward a DN interpretation. These effects hold regardless of pragmatic context (i.e., speaker intent), suggesting that this is a true syntactic phenomenon.

The finding that the negative marker plays a crucial role in shaping interpretation of negative sentences is related to Déprez et al.'s (2015) findings for Catalan, described above in section 2.1. In their study, the presence of the negative marker following a negative subject also yielded more DN interpretations than when it was absent (see also Espinal et al. 2016). These findings thus serve to highlight the importance of the position of the negative marker relative to the negative phrase in shaping the interpretation of negative sentences in language more generally.

It is also notable that for the $2 \mathrm{Q}$ items in our study, speaker intent played the clearest role in shaping interpretation, the syntactic position of the negative marker not being pertinent here. This provides further evidence that the position of marker $-n$ 'trelative to the negative phrase has a privileged status in shaping interpretation: When this marker was removed, speakers more carefully tracked speaker intent (i.e., pragmatics) in selecting their interpretation. This finding is again in line with Blanchette's (2017) acceptability judgment results, in which sentences where the marker preceded the negative phrase (whether object or subject; see examples (3) and (5) in section 2.2 above) were judged significantly more acceptable than those where it followed a negative subject in canonical position.

6.2 ACOUSTIC CUES FOR NEGATIVE MEANINGS. Concurrent with the clear and reliable effect of syntax, we also found some cues in the speech signal that might be taken under consideration in the construction of theoretical models of English negation, and of negation in general. DN appeared to be the marked form in the 2Q condition, with significantly higher fo on subject no one. DN was also marked relative to $\mathrm{NC}$ and single negation in the object condition, in this case by shorter duration on the stressed syllable than in the other two conditions. In the subject condition, it is possible that the significant drop in $\mathrm{f0}$ on won't in the DN condition is also a reflection of its markedness. Our results therefore suggest that in English, DN is marked prosodically relative to $\mathrm{NC}$.

The general pattern of the markedness of $\mathrm{DN}$ in our data is in line with previous findings on prototypical NC languages, though further research is needed in order to draw clearer parallels with English. It might also be the case that, given the syntactic biases discussed above, stronger prosodic cues are needed to signal Object DN as well as Subject NC in Standard English, since these appear to be less natural for speakers. Notably, in the 2Q condition, the difference between 
DN and NC was marked by f0 in the DN condition on the subject and not the object, suggesting that the sentence-initial negative constituent in these sentences may be the bearer of contrast.

6.3 BROADER IMPLICATIONS. Given that Standard English speakers typically do not use (or at least do not report to using) NC, a broader implication of the findings reported here is that grammars may have latent structures, or structures that can be generated but are not necessarily employed in usage, potentially for non-linguistic reasons such as normative pressure. A related conclusion is drawn in Etxeberria et al. (2018), in a comparative study of acceptability and interpretation judgments of negative sentences in Castilian, Basque Country Spanish, and Basque. On the basis of their experimental results, these authors conclude that because "ungrammatical sentences can also be interpreted reliably" (p. 14), they can also serve as an important data source in the construction of linguistic theories.

In our interpretation of the English data in Blanchette (2017) and those reported here, it appears that for Standard English speakers, it is not the case that "ungrammatical" sentences are nevertheless being interpreted reliably, but rather, that unacceptable sentences may display specific patterns of grammaticality. The acceptability judgment data show that binary acceptability obscures reliable syntactic preferences, which appear to reflect some underlying competence on the part of the speakers. In conjunction with the acceptability patterns, the fact that participants in our perception study reliably exploited both syntactic and acoustic information to interpret the auditory stimuli, which consisted of sentences they largely reported to not using, provides further evidence of the status of these sentences, both NC and DN, as grammatical in Standard English.

In sum, in conjunction with the results in Blanchette (2017), our data suggest that in the case of English negative sentences, low acceptability ratings observed only in binary or ternary terms obscure properties of a grammatical system. The idea of grammatical yet unrealized structures is not novel, and was first proposed by Barbiers (2009), in the context of a large-scale survey of dialect variation in Dutch. Such structures may form part of a speaker's competence, but may remain unused for non-linguistic reasons, including geographical separation between speakers and normative pressure.

In the case of English NC, it is clear that normative pressures shape its use and acceptability synchronically, as it remains heavily socially stigmatized in contemporary Englishspeaking society. If it is the case that NC is grammatical but un- or under-realized in the usage of Standard English speakers, as our data suggest, then this presents further support for the hypothesis that grammars have latent structures, and that non-linguistic forces cause these structures to remain hidden from view, unless investigated experimentally. Our work further shows several ways in which experimental methods and quantitative analyses may be employed to uncover some properties of these latent structures. In addition, it suggests that principled investigation of Standard language speaker knowledge of stigmatized structures could contribute important information to our understanding of linguistic variation more generally.

\section{References}

Barbiers, Sjef. 2009. Locus and limits of microsyntactic variation. Lingua 119:1607-1623.

Bates, Douglas, Martin Maechler, Ben Bolker, and Steve Walker. 2015. Lme4: Linear mixedeffects models using Eigen and S4. R package version 1.1-10. https:// github.com/lme4/lme4pureR. 
Blanchette, Frances. 2013. Negative concord in English. Linguistic Variation 13: 1-47.

Blanchette, Frances. 2015. English negative concord, negative polarity, and double negation. $\mathrm{PhD}$ Dissertation, CUNY Graduate Center. http://ling.auf.net/lingbuzz/002654.

Blanchette, Frances. 2017. Microsyntactic variation in English Negative Concord. Glossa: a journal of general linguistics 2: 1-32.

Blanchette, Frances \& Marianna Nadeu. 2018. Prosody and the meanings of English negative indefinites. http://ling.auf.net/lingbuzz/003667.

Boersma, Paul \& David Weenink. 2016. Praat: Doing phonetics by computer. http://www.praat.org/.

Cummins, Fred, Colin Doherty, and Laura Dilley. 2006. Phrase-final pitch discrimination in English. In Proceedings of Speech Prosody 2006, eds. Rüdiger Hoffmann and Hansjörg Mixdorff, 5467-5470. Dresden, Germany: TUDpress Verlag der Wissenschaften GmbH.

Davidson, Lisa. 2006. Comparing tongue shapes from ultrasound imaging using smoothing spline analysis of variance. The Journal of the Acoustical Society of America 120(1): 407-415. https://doi.org/10.1121/1.2205133.

Déprez, Viviane. 2011. Atoms of negation: An outside-in micro-parametric approach to negative concord. In The Evolution of Negation: Beyond the Jespersen Cycle, eds. Richard Ingham and Pierre Larrivée, 221-272. Berlin: Mouton de Gruyter.

Déprez, Viviane, Susagna Tubau, Anne Cheylus, and M. Teresa Espinal. 2015. Double Negation in a Negative Concord language: An experimental investigation. Lingua 163: 75-107.

Déprez, Viviane \& Jeremy Yeaton (to appear). French negative concord and discord: An experimental investigation of contextual and prosodic disambiguation. Proceedings of LSRL 46.

Espinal, M. Teresa and Pilar Prieto. 2011. Intonational encoding of double negation in Catalan. Journal of Pragmatics 43: 2392-2410.

Espinal, M. Teresa \& Susagna Tubau. 2016. Interpreting argumental n-words as answers to negative questions. Lingua 177: 41-59.

Espinal, M. Teresa, Susagna Tubau, Joan Borràs-Comes, and Pilar Prieto. 2016. Double negation in Catalan and Spanish: Interaction between syntax and prosody. In Negation and Polarity: Experimental Perspectives, eds. Pierre Larrivée and Chungmin Lee, 145-176. Cham: Springer.

Etxeberria, Urtzi, Susagna Tubau, Viviane Déprez, Joan Borràs-Comes, \& M. Teresa Espinal. 2018. Relating (un)acceptability to interpretation: Experimental investigations in negation. Frontiers in Psychology 8: Article 2370. https://doi.org/10.3389/fpsyg.2017.02370.

Geurts, Bart. 1998. The mechanisms of denial. Language 74: 274-307.

Gu, Chong. 2014. Smoothing spline ANOVA models: R Package GSS. Journal of Statistical Software 58(1): 1-25. https://doi.org/10.18637/jss.v058.i05.

Horn, Laurence R. 2010. Multiple negation in English and other languages. In The Expression of Cognitive Categories: Expression of Negation, ed. L. Horn, 117-48. Berlin, DEU: Walter de Gruyter.

Labov, William, Paul Cohen, Clarence Robins, and John Lewis. 1968. A study of the Nonstandard English of Negro and Puerto Rican speakers in New York City, Final Report. Cooperative Research Project No. 3288, United States Office of Education.

Ladusaw, William A. 1992. Expressing negation. Semantics and Linguistic Theory (SALT) 2. 237-260. https://doi.org/10.3765/salt.v2i0.3030. 
Liberman, Mark \& Ivan Sag. 1974. Prosodic form and discourse function. In Michael W. La Galy, Robert A. Fox, \& Anthony Bruck (eds.), Papers from the Tenth Regional Meeting of the Chicago Linguistic Society, 416-427. Chicago: Chicago Linguistic Society.

Lippi-Green, Rosina. 1997. English with an Accent. London \& New York: Routledge.

Longobardi, Giuseppe. 2014. Theory and experiment in parametric minimalism: The case of Romance negation. In Rob Pensalfini, Myfany Turpin, \& Diana Guillemin (eds.), Language Description Informed by Theory, 217-262. Amsterdam: John Benjamins.

Mathes, Timothy K. 2015. Consonant-Tone Interaction in the Khoisan Language Tsua. Doctoral Dissertation, New York University. https://ling.auf.net/lingbuzz/002725.

Nevalainen, Terttu. 1998. Social mobility and the decline of Multiple Negation in Early Modern English. In Jacek Fisiak and Marcin Krygier (eds.) Advances in English Historical Linguistics (1996), 263-291. Berlin/New York: Mouton de Gruyter.

Prieto, Pilar, Joan Borràs-Comes, Susagna Tubau \& M. Teresa Espinal. 2013. Prosody and gesture constrain the interpretation of double negation. Lingua 131:136-150.

Psychology Software Tools, Inc. 2012. E-Prime 2.0. http://www.pstnet.com.

Schellenberg, E. Glenn. 2002. Asymmetries in the discrimination of musical intervals: going outof-tune is more noticeable than going in-tune. Music Perception 19:223-248.

Simonet, Miquel, Marcos Rohena-Madrazo, \& Mercedes Paz. 2008. Preliminary evidence for incomplete neutralization of coda liquids in Puerto Rican Spanish. In Colantoni, Laura and Jeffrey Steele (eds.), Selected Proceedings of the 3rd Conference on Laboratory Approaches to Spanish Phonology, 72-86. Somerville, MA: Cascadilla Proceedings Project. http://www.lingref.com, document \#1715.

Thornton, Rosalind, Anna Notley, Vincenzo Moscati, \& Stephen Crain. 2016. Two negations for the price of one. Glossa: A Journal of General Linguistics 45. 1-30.

Wolfram, W. and R. Fasold. 1974. The study of social dialects in American English. New Jersey: Prentice Hall.

Xu, Yi. 2013. ProsodyPro-A tool for large-scale systematic prosody analysis. In Proceedings of Tools and Resources for the Analysis of Speech Prosody: 7-10. Aix-en-Provence, France.

Zeijlstra, H. 2004. Sentential Negation and Negative Concord. PhD Dissertation, University of Amsterdam. 